\title{
Ecological restoration: A new frontier for nature conservation and economics
}

\author{
James Aronson ${ }^{\mathrm{a}, \mathrm{b}_{i *}}$, Andre F. Clewell ${ }^{\mathrm{c}}$, James N. \\ Blignaut $^{\mathrm{d}}$, Sue J. Milton ${ }^{\mathrm{e}, \mathrm{f}}$
}

\author{
${ }^{\wedge}$ Restoration Ecology Group, CEFE (CNRS-UMR 5175) Montpellier, France \\ ${ }^{b}$ Missouri Botanical Garden, USA \\ ${ }^{C}$ A.F. Clewell, Inc., 5351 Gulf Drive \#5, Holmes Beach, FL 34217-1954, USA \\ ${ }^{d}$ Department of Economics, University of Pretoria, Lynnwood Road, Pretoria 0002, South Africa \\ ${ }^{e}$ Conservation Ecology Department, University of Stellenbosch, South Africa \\ ${ }^{f}$ The FitzPatrick Institute, University of Cape Town, South Africa
}

\begin{abstract}
Summary
Ecological restoration is still perceived by many conservationists, and the majority of economists, as a diversion, a delusion, and - far worse - a waste of money. In this paper we point out that restoration is in fact complementary not only to nature conservation but also to sustainable, equitable socio-economic development. This is because restoring and augmenting the natural capital base generates jobs and improves livelihoods and the quality of life of all in the economy.

In developing countries, where most biodiversity hotspots occur, both conservation of nature and the restoration of degraded ecosystems will find local support only if they are clearly linked to socio-economic development. Conversely, sound socio-economic development in the environmentally damaged portions of those countries undoubtedly will require ecological restoration of the natural capital base. Nature conservation, ecological restoration, and sustainable economic development policies should therefore be planned, budgeted and executed conjointly. ( 2006 Elsevier GmbH. All rights reserved.
\end{abstract}

Keywords: Biodiversity; Ecological restoration; Ecosystem services; Natural capital; Social capital

\section{Introduction}

Ecological restoration (ER) can be defined as "the process of assisting the recovery of an ecosystem that has been degraded, damaged or destroyed" (SER 2004). To this bare-bones definition, we would add that ER is a process that recovers and improves the functionality of ecosystems within landscapes consisting of lands in agricultural production as well as set-aside nature reserves. Restoration ecology is the science behind - and alongside - the practice of ER. Assisting ecosystem recovery augments biodiversity, and ecosystem services, at the landscape scale. Most conservation efforts focus on set aside land- or seascapes that are clearly demarcated and considered to be relatively 'intact', 'natural' or otherwise of significant conservation value. Ecological restoration is concerned both with these set-aside, protected areas and with the utilised portions of natural environments where people live, grow food and extract natural resources (Blignaut et al. in press). The concept of humans as integral members of ecosystems has been widely endorsed globally, as witnessed by UNESCO's definition of biosphere reserves as "areas of terrestrial and coastal ecosystems promoting solutions to reconcile the conservation of biodiversity with its sustainable use". Additionally, ecological restoration was described as "a means of conserving biodiversity and sustaining livelihoods" in a recent "call to action" issued by the ecological restoration joint working group of the Society for Ecological Restoration International and the 
IUCN Commission on Ecosystem Management (SER/IUCN: Commission on http://www.ser.org/content/Globalrationale.asp). Happily, the notion of ecological restoration is now entering popular culture, public policy, and education at a remarkably fast rate, especially in North America, Australia, South Africa, and also in some parts of Europe. Faced with our rapidly growing ecological footprint, and the mounting number of ecological crises worldwide, ecological restoration clearly has a key role to play in conserving species, and natural capital, and for improving human well-being - both materially and culturally (Harris et al. in press; Leigh 2005; Van Andel \& Aronson 2006). In this introductory paper, and in the invited papers which follow, we briefly explore the views of those antagonistic towards restoration, provide a rebuttal, and then explain why restoration, conservation and sustainable economic development are mutually complimentary, and that the conceptual and practical boundaries among them are becoming increasingly blurred. An important step awaiting us is to further splice the science and the practice of these three interrelated activities, even as the range of landscapes that we see-natural, seminatural and cultural, etc. - become more complex (Machado 2004). In the concluding essay, we offer a brief overview, and a glimpse of the way forward.

\section{Why not to restore?}

Natural areas everywhere are being converted and 'sacrificed' for short-term economic gain at an ever-increasing rate by an ever-growing human population (Millennium Ecosystem Assessment 2005). The threshold of socio-economic sustain-ability has been surpassed in most nations and regions of the world. Because social sustainability ultimately depends on ecological sustainability, this trend must be reversed.

Yet opponents of ecological restoration argue that restoration is encroaching on the chronically dismal budgets for conservation and rural development, and that funding and policy should focus on preservation and sustainable development, and not on 'expensive', long-term restoration. Investment to conserve what remains of 'wild' nature now appears as common sense, and remains as a high priority among conservationists (Balmford et al. 2002). Many deep ecologists, as well as development interests, argue that restoration takes too long to have meaningful impact on necessary conservation or economic development programmes. Others, particularly those motivated by idealistic sentiments, reject economic pragmatism and find it offensive to 'put a price tag on nature' (Stevenson 2000, in response to Clewell 2000; cf. reply to Stevenson 2000, by Aronson \& Le Floc'h 2000).

However, in developing countries - where most biodiversity, and most poverty, malnutrition, war and disease, are concentrated, and where most biodiversity 'hotspots' also occur - both the restoration of degraded ecosystems and landscapes, and the conservation of nature, will only find support if they are clearly linked to sound socio-economic research and development as well as job creation and training. Thus, holistic reasons and integrated arguments for restoration must be articulated and communicated. We maintain that the continual investment of financial, human and social capital in the restoration of damaged and depleted ecosystems has become essential to assure our ecological sustainability (see Cairns 1993; Janzen 2002; Repetto 1993). Development and resource use simply cannot be sustainable unless they are designed and managed so that damage is repaired whenever it occurs. That is a pragmatic, survival policy.

\section{Why restore natural capital? Pragmatic reasons and a strategic approach}

Clewell and Aronson (2006) describe five main motivations to restore degraded ecosystems, including idealistic, technocratic, heuristic, biotic and pragmatic. The pragmatic rationale for ecological restoration was described as consisting of two components - the restoration of 'natural capital' (RNC) and climate amelioration. However, the RNC approach to ecological restoration can effectively be viewed as an umbrella strategy with many spokes, including the other motivations identified above. Each spoke represents a different tactic that can and will vary in relative importance depending on the specific scale, site and context at hand. Like a person holding an umbrella in a rainstorm, society can and should put up an RNC umbrella to help weather the storm of global environmental change. If idealistic, technocratic, heuristic or biotic reasons to restore are invoked alone, then it is only rich nations that can readily afford such an investment. Poorer, 
developing countries need restoration to augment natural capital but there, as in the rich countries, idealistic motivations for ER are also valued.

\section{What are the tactics of RNC? We suggest some of the following}

(1) Mainstreaming, i.e. bringing the benefits and motivations into the common discourse of the general public, so that it becomes taken for granted.

(2) Creating employment and livelihoods, and striving to restore social capital, defined as institutions, relationships, social networks, and shared cultural beliefs and traditions that promote mutual trust.

(3) Enhancing services and goods within timescales that benefit individuals.

(4) Using those approaches that are locally affordable and ecologically and culturally appropriate, taking cognisance of mindsets and specific settings.

(5) Restoring self-sustaining ecosystems that need little or no ongoing management.

(6) Planning with local users so that all tangible and intangible values of restoration can be appreciated and the action supported.

Not all of these tactics are not considered when motivation is technocratic, biotic, heuristic or idealistic. However, we argue that RNC as a strategy embraces all the other motivations for restoration and will go the furthest in efforts to reestablish a healthy, sustainable, matrix for human endeavour. A pertinent example is the ten-year-old Working-for-Water programme in South Africa (Milton, Dean, \& Richardson 2003; Van Wilgen et al. 2004) - a public works initiative in which more than thirty thousand people are currently employed to eradicate invasive alien woody plants (especially deep-rooted Australian acacias) that absorb and transpire soil moisture and thereby deprive native plants, agricultural lands, and people, of much-needed water. Jobs, livelihoods and a renewed social capital are being created in this programme while the first step of restoring natural - native - landscapes is being carried out through the elimination of invasive and water-intensive alien plant species along rivers and streambeds where they proliferate. In this programme, however, restoration is conducted as a development strategy, which simultaneously addresses conservation concerns. In this way, restoration opens a new frontier for both conservationists and economists alike to find a common cause and an R \& D platform upon which to dialogue and cooperate. Problems exist (Woodworth 2006), but this programme offers an outstanding model for study.

Ecologist Daniel Janzen has made lasting contributions not only to theoretical ecology, but also to the science and practice of nature conservation and ecological restoration. In his writings, he has forcefully argued in favour of utilising wildland biodiversity in such a way that it can pay for its own conservation (Janzen 2001, 2002). This implies that nature conservation, quality of life, development and commercialisation are complimentary. As Daily and Ellison (2002) put it, it is possible, and we should strive to "make conservation profitable" (cf. Holl \& Howarth 2000). However, this will require profound changes in our economic models and in the public policies based upon them (Aronson, Milton, Blignaut in press; Milton, Aronson, \& Blignaut 2005).

Restoration is the acknowledgement by humans that we have used too much natural capital and that - for our own good - it is now time to 'give back' to nature and to nature's functions on which we depend. It attempts to increase the pool (or stock) of existing natural capital by complimenting conservation efforts outside demarcated conservation enclaves, when and where natural capital stocks have become dangerously depleted (Fig. 1).

This figure illustrates that people extract and use natural resources in various ways that can, and often do, have negative impacts on the stock of natural capital, as well as the availability of ecosystem goods and services. The difficulty and cost of restoring natural capital is usually a function of the extent of degradation (Aronson et al. in press; Hobbs a Norton 1996). This consequence should be considered when planning and budgeting to use or extract natural resources. Communities and societies can also decide to offset the negative impacts of resource 


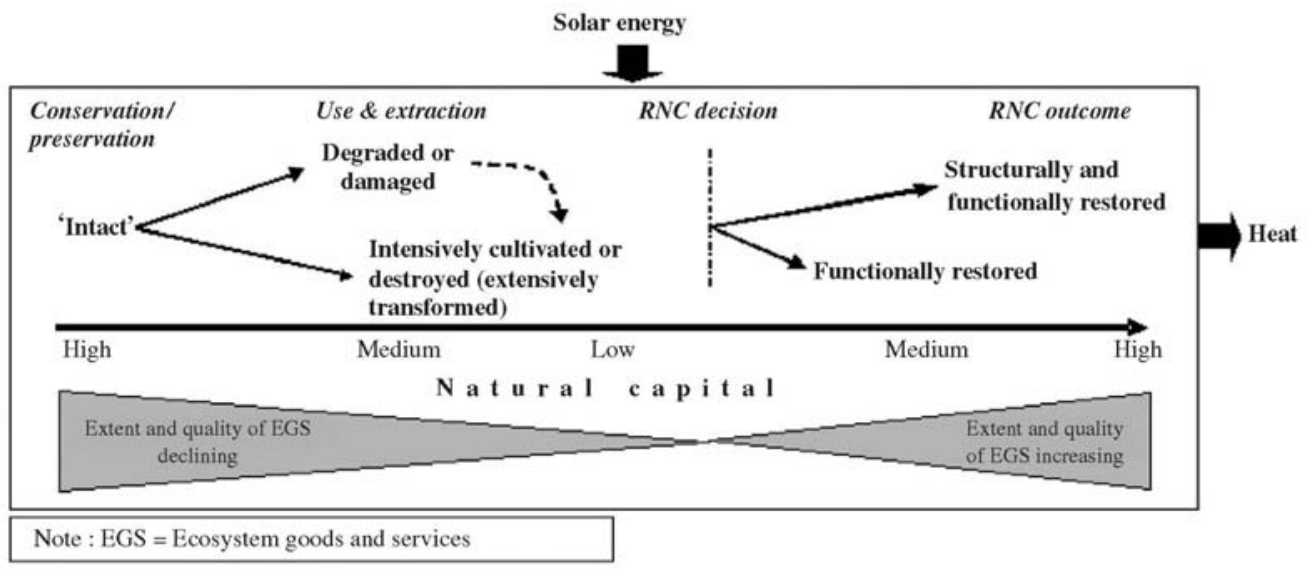

Figure 1. Schematic description of the ebb and flow of natural capital (above) and ecosystem goods and services (below) as a function of human decisions, within the biosphere which depends on solar energy and gives off low-grade energy in the form of heat. This scheme does not suggest that all use and extraction lands should be restored. Instead applies only to lands that are to be re-dedicated to providing flows of natural goods and services through restoration.

extraction by investing in ecosystem protection, sustainable use technologies, and the restoration of natural capital. At the top left of Fig. 1, the decision to conserve reflects the sensible desire to protect the remaining natural capital of intact ecosystems. Further to the right, "RNC decision" reflects the policy and management intervention inspired by the various motivations to restore degraded ecosystems, as discussed in the previous section. The level of financial investment and social commitment - as well biophysical constraints - will determine the degree of conservation, restoration or natural capital augmentation (low, medium, high). Insisting on the natural capital approach to these issues can help focus the discussions leading to collective decisions.

Ecological restoration is portrayed as a strategy that augments natural capital. Investing in restoring natural capital does not detract from nature conservation, but rather adds additional meaning, relevance and effectiveness to conservation efforts. For example, restoring corridors between disjointed protected areas can maintain a population that might otherwise die out due to habitat fragmentation. In addition, restoration can provide new jobs, even as it increases the stock of natural goods and services on which all economies depend. Ecological restoration - if done holistically -increases economic opportunities and benefits, while also enhancing the social, cultural, psychological and spiritual aspects of human welfare.

In summary, well-conceived and executed restoration of natural capital requires the melding of the technocratic, heuristic, biotic and idealistic rationales, as well as pragmatism. To do so, institutions that conduct technocratic restoration must relinquish some authority and actively work in partnership with stakeholders. Conversely, stakeholders - particularly local citizenry - must be motivated to assume responsibility in a partnership and inject restoration projects with idealism, cultural meaning and heuristic value. Through such a coalition approach, the priorities will be met of both conservationists, who seek to maximise net biodiversity growth and system function, and of economists, who seek to maximise financial return and promote economic growth as a means to creating employment opportunities, to banish poverty, hunger and homelessness, and to improve the lives of most people.

\section{Acknowledgements}

The authors warmly thank Oonsie Biggs, Andy Carey, Jeff Herrick and Paddy Woodworth for their helpful comments on the manuscript. We thank Christelle Fontaine for all her help, and our superb team of contributors. We send un abrazo to our friend Antonio Machado for the invitation to put together this special issue on restoration, and his feedback and encouragement along the way. James Aronson gratefully acknowledges the European Commission for support of the 
CREOAK project FP5: QLRT-2001-01594, during the period when this special issue was assembled. SJM's research contribution to this work was partly supported by the National Research Foundation of South Africa under Grant number 2053674. We also wish to acknowledge the support of the Bilateral Project 17370 of the French CNRS and South African NRF Cooperation Agreement, without which this project could not have been achieved.

\section{References}

Aronson, J., \& Le Floc'h, E. (2000). Restoration of natural capital: Pros and problems. Restoration Ecology, 8, 214-216.

Aronson, J., Milton, S. J., \& Blignaut, J. N. (Eds.), (in press). Restoring natural capital: Science, business and practice. Washington, DC: Island Press.

Balmford, A., Bruner, A., Cooper, P., Costanza, R., Farber, S., Green, R. E., et al. (2002). Economic reasons for conserving wild nature. Science, 297, 950-953.

Blignaut, J. N., Aronson, J., Archer, S., Clewell, A. F, Woodworth, P., \& Desai, N. (in press). The values and ethics of restoring natural capital. In J. Aronson, S. J. Milton \& J. Blignaut (Eds.), Restoring Natural Capital: Science, Business and Practice. Washington, DC: Island Press.

Cairns, J., Jr. (1993). Ecological restoration: Replenishing our national and global ecological capital. In D. Saunders, R. Hobbs, \& P. Ehrlich (Eds.), Nature conservation 3: Reconstruction of fragmented ecosystems (pp. 193-208). Chipping Norton, New South Wales: Surrey Beatty \& Sons.

Clewell, A. F (Ed.). (2000). Editorial: Restoration of natural capital. Restoration Ecology, 8, 1.

Clewell, A. F, \& Aronson, J. (2006). Motivations for the restoration of ecosystems. Conservation Biology, 20(2), 420^28.

Daily, G. C, \& Ellison, K. (2002). The new economy of nature. Washington, DC: Island Press.

Harris, J. A., Hobbs, R. J., Higgs, E., \& Aronson, J. (in press) Ecological restoration and global climate change. Restoration Ecology.

Hobbs, R. J., \& Norton, D. A. (1996). Towards a conceptual framework for restoration ecology. Restoration Ecology, 4, 93-110.

Holl, K., \& Howarth, R. (2000). Paying for restoration. Restoration Ecology, 8, 260-267.

Janzen, D. H. (2001). Lumpy integration of tropical wild biodiversity with its society. In W. J. Kress, \& G. W. Barrett (Eds.), A new century of biology (pp. 133-148). Washington, DC: Smithsonian Institution Press.

Janzen, D. H. (2002). Tropical dry forest restoration: Area de Conservacion Guanacaste, northwestern Costa Rica. In M. R. Perrow, \& A. J. Davy (Eds.), Handbook of ecological restoration. Restoration in practice, Vol. 2 (pp. 559-584). Cambridge, UK: Cambridge University Press.

Leigh, P. (2005). The ecological crisis, the human condition, and community-based restoration as an instrument for its cure. Ethics in Science and Environmental Politics, 2005, 3-15.

Machado, A. (2004). An index of naturalness. Journal for Nature Conservation, 12, 95-110.

Milton, S. J., Aronson, J., \& Blignaut, J. (2005). Unite to save Earth's capital. Quest (South African Academy of Science), 2(1), 39^1.

Milton, S. J., Dean, W. R. J., \& Richardson, D. M. (2003). Economic incentives for restoring natural capital in southern African rangelands. Frontiers in Ecology and the Environment, 1, 247-254.

Millennium Ecosystem Assessment. (2005). Ecosystems and human well-being: Synthesis (160 pp.). Washington, DC:Island Press; CA: Covelo.

Repetto, R. (1993). Government policy, economics and the forest sector. In K. Ramakrishna, \& G. Woodwell (Eds.), Forests for the future: Their use and conservation (pp. 93-110). New York: Yale University Press.

SER. (2004). The SER primer on ecological restoration. Society for Ecological Restoration, Science and Policy Working Group, www.ser.org.

Stevenson, M. J. (2000). Problems with natural capital: A response to Clewell. Restoration Ecology, 8, 211213.

Van Andel, J., \& Aronson, J. (Eds.). (2006). Restoration ecology: The new frontier. Oxford, UK: Blackwell Science.

Van Wilgen, B. W., de Wit, M. P., Anderson, H. J., Le Maitre, D. C, Kotze, I. M., Ndala, S., et al. (2004). Costs and benefits of biological control of invasive alien plants: Case studies from South Africa. South African Journal of Science, 100, 113-122.

Woodworth, P. (2006). What price ecological restoration. The Scientist, 20(4), 38-45. 